\title{
CURRENT TRENDS IN OCCUPATIONAL PSYCHOLOGY
}

\begin{abstract}
A DIsCUSSION on "Current Trends in Occupational Psychology" occupied the morning session on August 10 of Section J (Psychology) of the British Association. The first contributor was Dr. C. B. Frisby, director of the National Institute of Industrial Psychology. Dr. Frisby began by tracing the development of industrial psychology in Britain during the past thirty years. For most of this period, emphasis had been laid on the investiga. tion of capacities rather than inclinations, and on the use of laboratory methods of inquiry. The Haw. thorne studies, and fuller employment, had then caused attention to become focused on conditions affecting motivation at work. In consequence, the industrial psychologist had had to devote more of his time to field investigations; and these had produced new methodological problems.
\end{abstract}

Dr. Frisby illustrated his contentions by references to three post-war inquiries carried out by the National Institute of Industrial Psychology. One was into joint consultation. It was a study of current practice, and an attempt to identify factors apparently associated with successful joint consultation. The second was designed chiefly to survey current practice in regard to the status, selection and training of supervisors in industry; but was aimed in addition at the improvement of existing selection and training procedures. The object of the third investigation was to discover principles governing the determination of optimum units of work in repetitive tasks that had been greatly subdivided. "It is clear that at some point in the breaking-down process, for a variety of reasons, the operative will become less effective than he was with the larger task. The problem was how to give some guidance to the production engineer in identifying this point."

All three investigations demonstrated the need for sound means of assessing attitudes to work and satisfactions derived from working conditions; and a basic methodological problem was that of finding ways of doing this which would be adequate and acceptable but not time-consuming. Dr. Frisby said that attitude scales have possibilities that should be more thoroughly explored in Britain; but that the interview is usually to be preferred, and interviewing skill is of great importance to the industrial psychologist. Other problems thrown up by the three researches centred on consideration of criteria of occupational success, the most difficult-and perhaps the most important-of all the tasks facing the occupational psychologist.

Dr. N. A. B. Wilson, senior psychologist to the Admiralty, read a paper-part of which was heard by H.R.F. the Duke of Edinburgh-on "Applications of Psychology in the Defence Departments". Psychologists, he said, can scarcely be expected to abolish war. So far, with the possible exception of a few psychiatrists, they have not even proved very good at what is called psychological warfare, which is the art of winning wars without actually fighting, or basic warriorship. The activities of psychologists in the Defence Departments can, in fact, be grouped under two main headings: fitting the man to the job, and fitting the job to the man. In the first group are to be found problems arising in the improvement of methods of personnel selection, methods of training and examining (for example, aircraft pilots), and documentation (for example, at recruiting centres). In the second are problems arising in the improvement of methods of work (for example, gun drills), design and layout of equipment (such as aircraft cockpits), and living and working conditions (for example, operating conditions in extremes of climate). In the Admiralty, the Naval Motion Study Unit, which is the joint responsibility of the Director of Operational Research and the Senior Psychologist, has made proposals that would reduce by two the size of a gun-crew. The psychologist's contributions in this field were of two kinds. He advised on the design of experiments and on the criteria needed in the evaluation of proposed changes; and he advised on the needs and capacities of operators of equipment. His aim was to help to ensure that all drills and equipment prepared for Service use show the maximum possible adaptation to the needs and capacities of all probable users in all probable operational circumstances.

Dr. Wilson commented on five topics that seem likely to provide much work for military psychologists. First, man-power planning in terms of quality is now becoming possible. Given the composition of a naval entry in terms of classification test scores, and given a fairly stable connexion between those scores and advancement, useful estimates can be made of the petty officer material-judged by present standards-likely to be available in a few years time. Secondly, more consideration is being given to the utilization of marginal groups, including the very able or unusually qualified; the dull ; the physically substandard; 'high-grade funnies'; and the unstable. Thirdly, within the Services there are many organizational arrangements that would repay investigation in the light of what we now know about human abilities and interests. Fourthly, the educative function of Service psychologists should be develloped. For example, they could profitably make better known the advantages of 'over-learning' skills and providing trainees with knowledge of their own progress in training ; and of the proper co-ordination of control adjustments with related display changes in equipment design. There is also a need for the further ad hoc training of personnel selection officers to give day-to-day advice on matters, falling within their sphere, which the Service psychologists have no opportunity of considering, and for the provision of information, for the ordinary man in the tank or ship or aircraft, on the uses of applied psychology in warfare. Fifthly, it is becoming evident that there is a place for the discreet use of attitude and opinion surveys in the personnel work of the Services. Dr. Wilson concluded his paper, which was very well received, by directing attention to the need of the Services for psychologists who are competent theoretical men and methodologists.

A paper prepared by Dr. E. Anstey, head of the Civil Service Commission Research Unit, on "Applications of Psychology in the Civil Departments", was read by Mr. D. McMahon. It was concerned chiefly with the work of psychologists employed by the Civil Service Commission, either on the Civil Service Selection Board or in the Research Unit; but towards its close, passing reference was made to the 
place of psychologists on the Prison Commission and elsewhere.

Psychologists have made three distinctive contributions to the Civil Service Selection Board : first, in the planning of the work of the Board ; secondly, in bringing to its activities a certain quality of expert knowledge in the scientific study of personality; and thirdly, in insisting from the outset on the need for a well-designed follow-up scheme, from which an objective judgment of the value of the board's procedures could be obtained. The last of these contributions, Dr. Anstey believes, is the most important; and the outcome will be a series of reports, the first of which has already appeared.

The main activities of the Research Unit have been job analysis, test construction and follow-up. The follow-up has included an inquiry into the pregress of a hundred entrants to the Administrative Class who, being already employed in the Civil Service, did not go through the Civil Service Selection Board procedure. They had been given instead a more conventional written examination and board interview, though the board interview had been preceded by a private interview. The whole selection procedure had proved satisfactorily valid, when judged two years later by an overall grading of present performance; and the written examination alone had been found to have made a very useful contribution.

Dr. Anstey thinks that the time is ripe for psychologists in the Civil Service Commission to devote more time to discovering how to get the best out of people who have been selected. The incentives problem is of even greater importance in the Civil Service than in private industry. He wants to see more research done on the size and internal organization of the 'working group'; and on what he calls 'internal incentives', which would help individuals to make regular self-assessments of the quality and quantity of their work. $\mathrm{He}$ urged psychologists in the Civil departments to be clear in their own minds about the worthwhileness of their research projects before embarking on them; to make their reports intelligible to non-technical readers; and to aim at striking a satisfactory balance between a high professional standard and practical effectiveness.

Mr. Alec Rodger, reader in psychology at Birkbeck College, University of London, and consulting psychologist to the Admiralty and to the Central Youth Employment Executive, contributed a paper on "Vocational Guidance in Britain", in which he reviewed the past and present work of psychologists in this field and outlined several urgent problems. Conditions for research and development are now more favourable than they have ever been before, partly because the increasing need for the proper use of human resources in industry has directed attention to the advantages of sound guidance. This is shown in the new orientation of the Youth Employ. ment Service and in the work of the Ministry of Labour's Industrial Rehabilitation Units : in both, psychologists have a small but important place.

The most pressing need of all, Mr. Rodger said, is for the clarification of our concepts of occupational success and failure, for without this we shall continue to lack satisfactory criteria whereby to judge the worth of much of our other scientific and technological work. A second need is for better ways of studying the 'requirements' of occupations. Here we have been too long content with the listing of illdefined qualities that have been considered, on the basis of 'hunch', to be important. Empirical investigation is wanted, and it may well be founded provisionally on the notion that the best way to arrive at satisfactory conclusions about the requirements of an occupation is to study people who are acknowledged failures in it, and to compare them with people who are acknowledged successes. Thirdly, there is a need for a better functional classification of occupations. The conventional grouping of them, as concerned with ideas or things or people, is inadequate.

These papers seem to indicate clearly that occupa. tional psychologists in Britain are in considerably better intellectual health than they were in the years immediately before the War. In research and development alike, they are making substantial strides in industry and in the Service and Civil departments. The work of the Service departments is perhaps particularly impressive in its range and quality. The papers read at this discussion are to be published in book form by Messrs Methuen and Co., Ltd.

\section{TREND OF INORGANIC AND PHYSICAL CHEMISTRY SINCE 1850*}

$T$

H.E development of inorganic and physical chemistry during the past hundred years falls into two periods. Until the end of the nineteenth century these two branches of chemistry experienced a steady evolution, while their theoretical foundations, laid at the beginning of modern chemistry, remained unaltered; but about 1900 a revolution set in which changed these very foundations. The difference is as great as the contrast between the quiet security and constant progress of the Victorian age and the upheaval caused in this century by the two World Wars.

One of the greatest achievements during the first period was the discovery of the Periodic Law; it was based on Lavoisier's conception of the chemical element and on the atomic theory founded by Higgins and Dalton. No explanation for the Periodic Law could be given, and fantastic representations without scientific meaning were common; some unfortunate examples of this attitude can still be seen in the science exhibitions of London's Festival of Britain. A real understanding of the Periodic System only became possible after insight into the structure of matter had been gained, mainly as a consequence of the study of radioactive elements and their radiations. Radium was discovered by Pierre and Marie Curie in 1898 , the theory of radioactive disintegrations developed by Rutherford and Soddy in 1902. From this work and from the discovery of isotopy in 1913 by Soddy, J. J. Thomson and Aston, three very important facts emerged which were in contradiction with the doctrines of classical chemistry : (1) elements are not immutable; (2) atoms are complicated structures containing a tremendous store of energy ; (3) atomic weights are not fundamental constants. The recognition of these facts, and great strides made during the same period in experimental and theoretical physics, made it possible for Rutherford and Bohr to crown the old atomic theory by a theory of the atom. According to this theory the chemical character of

* Substance of a paper by Prof. F. A. Paneth, F.R.S., read on August 9 before Section $B$ of the British Association meeting at Edinburgh. 